\title{
Análisis de patrones espectrales del terreno y cambios hidrológicos a partir de datos multisensor en espacios naturales del sur de Costa Rica
}

Esono Mangue, Sofía, Rejas Ayuga, Juan Gregorio, Bonatti, J., Martínez Marín,Rubén, Marchamalo Sacristán, Miguel, Algeet, Nur, y Fernández Moya, Jesús

\section{Resumen:}

En Mayo del 2012, después de más de un año de investigación y planeación, un En el presente trabajo se aborda el estudio de los cambios en la cobertura del terreno y su impacto medioambiental en espacios naturales y semiurbanos del Sur de Costa Rica, incluida la reserva natural del Parque del Corcovado y la laguna de Sierpe.

Para ello, se han utilizado datos de los sensores aeroportados HyMAP y MASTER, así como imágenes ASTER y ETM+ en un período comprendido entre 1990 y 2010. Se ha analizado tanto la cobertura del suelo como las láminas de agua mediante clasificación digital supervisada con datos de radiometría de campo como indicativos de efectos debidos a una posible contaminación ambiental o sobreexplotación de recursos que pudieran estar afectando a la zona. Se exponen los primeros resultados obtenidos así como la cartografía generada, y se evalúa el estado y la evolución de los usos del suelo.

Palabras clave: hiperespectral / multiespectral / hidrología / cobertura del suelo / detección de cambios.

\section{Abstract:}

This study presents changes in land cover and its environmental impact in interest areas of natural and semi-urban zones of southern Costa Rica, including the nature reserve of the Corcovado Park and the Sierpe lagoon.

Data from HyMap and MASTER airborne sensors are used in this research, as well as ASTER and ETM+ images taken in a period between 1990 and 2010. Land co- 
ver and water surfaces are analyzed by supervised digital classification using radiometry data field, considered as indicative of possible environmental pollution or overexploitation of resources effects that could be affecting the area. Therefore, first obtained results and generated mapping are useful to assess the condition and evolution of land use.

Keywords: hyperspectral/multispectral/hydrology/land cover/change detection.

Esono Mangue, Sofía (sofia.esono@gmail.com), Universidad Politécnica de Madrid, UPM; Rejas Ayuga, Juan Gregorio (juangregorio.rejas@upm.es), Universidad Politécnica de Madrid, UPM; Bonatti, J. (jbonatti2011@gmail.com), Universidad de Costa Rica, UCR; Martínez Marín, Rubén (ruben.martinez@upm.es), Universidad Politécnica de Madrid, UPM; Marchamalo Sacristán, Miguel (miguel.marchamalo@upm.es), Universidad Politécnica de Madrid, UPM; Algeet, Nur (nuralgeet@gmail.com), Universidad Politécnica de Madrid, UPM; Fernández Moya, Jesús (jesusfmoya@gmail.com), Universidad Politécnica de Madrid, UPM. 


\section{INTRODUCCIÓN}

Se ha venido observando por instituciones y organismos científicos costarricenses un cambio significativo en las coberturas naturales y en espacios semiurbanos en una amplia región al sur de Costa Rica, concretamente en las inmediaciones del Parque Nacional de Corcovado, en un período desde que se registran datos fiables de al menos 3 décadas a esta parte. Estos cambios de las cubiertas pudieran estar asociados a su vez a cambios de usos del suelo, cambios de cultivos, como efectos de causas naturales, deforestación, contaminación o debidos a sobre explotación de los mismos.

Para estudiar los efectos producidos por la dinámica de cambio en la cobertura del terreno se viene aplicando con éxito la monitorización mediante sensores de teledetección (E. Chuvieco 2002), así como análisis cuantitativo en conjunción con Sistemas de Información Geográfica (Bosque Sendra et al. 2010; Conesa García et al. 2004). De esta manera, se elaboran productos cartográficos diversos sobre el estado y la evolución de las coberturas naturales y artificiales del terreno (C.M. Marino et al. 2001; J.G. Rejas Ayuga et al. 2007), y se generan nuevas variables sobre los parámetros biofísicos que pudieran estar evolucionando en un amplio período temporal en una zona como investigada especialmente sensible a los efectos del cambio global.

En este sentido, la tecnología hiperespectral o espectrometría de imagen, supone una mejora que ofrece información global de una amplia área de estudio además de una elevada definición espectral necesaria para caracterizar las cubiertas en estas zonas. Las investigaciones se han dirigido hacia propuestas de optimización de procesos de clasificación a partir de datos multi-sensor de alta resolución. Experiencias previas de clasificación de datos hiperespectrales se han mostrado de gran utilidad en la cartografía de biotopos y en el apoyo de la gestión del territorio en estos espacios (Landgrebe, D. 1999; Mckeown et al. 1999).

En el presente estudio se ha tenido en cuenta datos multi-hiperespectrales para realizar una aproximación sobre la caracterización espectral de espacios naturales y espacios semiurbanos, validando los resultados con espectrorradiometría de campo y laboratorio. Se han analizado cambios en la reflectividad y emisividad de las coberturas del terreno y de láminas de agua indicativos de efectos debidos a una posible contaminación ambiental o sobre explotación de recursos que pudieran es- 
tar afectando a la zona. Se presentan los primeros resultados obtenidos, así como la evolución en las coberturas del terreno indicativas de la dinámica de los cambios de los usos del suelo.

\section{AREAS DE ESTUDIO}

El estudio se ha centrado en las áreas del Parque Corcovado y la laguna de Sierpe, en la región suroeste de Costa Rica. El Parque Nacional (PN) Corcovado se encuentra en la Península de Osa y es parte del Área de Conservación Osa (Provincia de Puntarenas) (Figura 1). Fue creado el 24 de octubre de 1975 y comprende un área de 45.757 hectáreas terrestres y 5.375 marinas (MINAE y SINAC 1999). Una meteorización geológica intensa ha producido una topografía de riscos angostos, lomas largas y empinadas, y una red de drenaje que domina prácticamente todas las tierras excepto una meseta en la zona noroeste del parque.

El PN Corcovado es considerado una pieza muy importante en el amplio sistema de parques nacionales y reservas biológicas del país (Hartshorn et al. 1983). La diversidad biológica es sorprendente, tanto que National Geographic lo ha denominado "el lugar más intenso del mundo, biológicamente hablando" y se estima que ningún lugar en el mundo (que posea una extensión similar) albergue una diversidad biológica mayor (MINAE \& FPN 1999).

La laguna de Sierpe está situada al sureste de Costa Rica (Figura 2), a una altitud de $16 \mathrm{msnm}$ (Haberyan et al, 2003) y tiene 1,02 $\mathrm{km}^{2}$ de espejo de agua (Umaña et al, 1999), siendo su área de cuenca de 306,54 km².

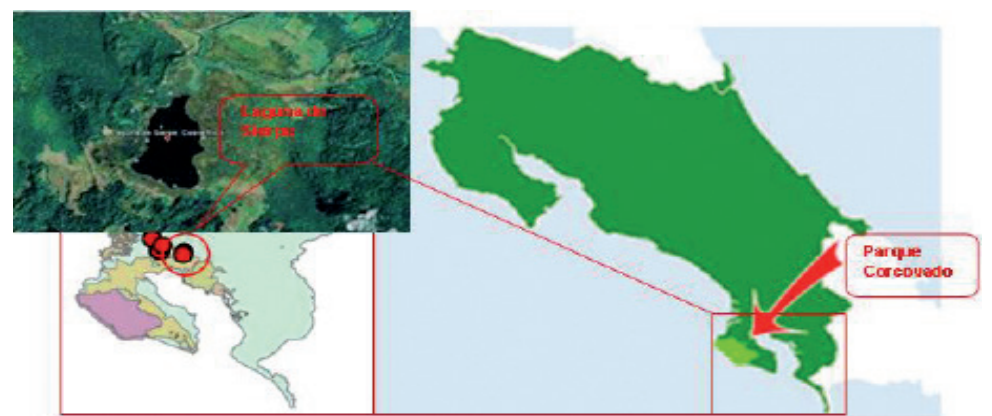

FIGURAS 1 y 2. Localización del Parque Nacional de Corcovado y la laguna de Sierpe. Fuente: 2007-2012 YourTravelmap.com, Tribunal Ambiental Administrativo (TAA) y Ministerio de Ambiente, Energía y Telecomunicaciones (MINAET) de Costa Rica - 2011). 


\section{DATOS Y PREPROCESO}

Los datos de teledetección utilizados en este estudio son de dos tipos: hiperespectrales aeroportados y multiespectrales espaciales. Se han utilizado datos del sensor HyMAP (Cocks et al., 1998), sensor aeroportado e hiperespectral desarrollado por Integrated Spectronics, en Sydney, Australia, y operado por HyVista Corporation. Ofrece una excelente información espacial, espectral y radiométrica, en un número de bandas (Tabla 1) que en los últimos prototipos es configurable, abarcando rangos del espectro reflectivo hasta el infrarrojo de onda corta o SWIR (Short Wave InfrRed). El sistema consiste en un escáner "whiskbroom" que utiliza redes de difracción y cuatro matrices compuestas por 32 elementos para proporcionar 126 canales espectrales que cubren un rango de 0,45 a 2,5 micras y se extienden sobre una franja de 512 píxeles.

También se han utilizado datos del sensor MASTER, similar al MAS (IS Airborne Simulator), con bandas térmicas modificadas asemejándose más al NASA EOS ASTER (Advanced Spaceborne Thermal Emission and Reflection Radiometer), que fue lanzado en el año 1998. Se pretendió con él estudiar las propiedades geológicas y otras características de la superficie terrestre. Sus 50 bandas espectrales están configuradas de la siguiente manera (Tabla 2):

\begin{tabular}{|l|l|l|l|l|}
\hline \multicolumn{5}{|c|}{ Configuración espectral } \\
\hline Módulo & Canales (bandas) & Rango espectral $(\mu \mathrm{m})$ & Ancho banda (nm) & Media espectral (nm) \\
\hline VIS & 1 al 31 & $0.45-0.89$ & $15-16$ & 15 \\
\hline NIR & 32 al 62 & $0.89-1.35$ & $15-16$ & 15 \\
\hline SWIR1 & 63 al 93 & $1.40-1.80$ & $15-16$ & 13 \\
\hline SWIR2 & 94 al 125 & $1.95-2.48$ & $18-20$ & 17 \\
\hline
\end{tabular}

TABLA 1. Características del sensor HyMAP. (Fuente: modificado de Clocks et al., 1998).

\begin{tabular}{|l|l|l|}
\hline Canal espectral & Banda: Intervalo espectral $(\mu \mathrm{m})$ & Espectro \\
\hline l a 7 & $0.460-0.75$ & Visible \\
\hline 8 a 25 & $0.8-2.39$ & Infiarojo cercano (NIR) \\
\hline 26 a 40 & $3.15-5.25$ & infrarrojo medio \\
\hline 41 a 50 & $7.9-12.75$ & infrarrojo lejano \\
\hline
\end{tabular}

TABLA 2. Características de las bandas del sensor MASTER. (Fuente: modificado NASA). 
La imagen HyMAP utilizada tiene un tamaño de 512 x 4564 píxeles, tomada el día 12-09-2003 y con una resolución espacial de 15 metros (Figura 3). La imagen MASTER fue adquirida en tandem con HyMAP el mismo día, siendo su tamaño de 6973 líneas y 750 columnas, con una resolución espacial de $20 \mathrm{~m}$.

Se han utilizado imágenes en ETM+ de 7741 x 6911 píxeles, tomadas con fecha 02-02-1990, 14-02-2000 y 20-02-2011 y con una resolución de 30 metros, procedentes de Earth Explorer del USGS (Figura 4).

Se ha realizado un procesamiento digital de imágenes mediante la aplicación de técnicas matemáticas computacionales para permitir mejorar, corregir, analizar y extraer información de las imágenes captadas por el conjunto de los sensores. Ha sido necesario transformar los parámetros de las imágenes a una escala absoluta, tanto espacial como espectral, de tal manera que podamos referir las medidas extraídas a otras procedentes de los distintos sensores o tomadas en distintas fechas. El objetivo es preparar el conjunto de los datos para posteriores análisis que permitan correlacionar espacialmente las coberturas del terreno con los parámetros biofísicos de reflectividad, temperatura superficial o profundidad.

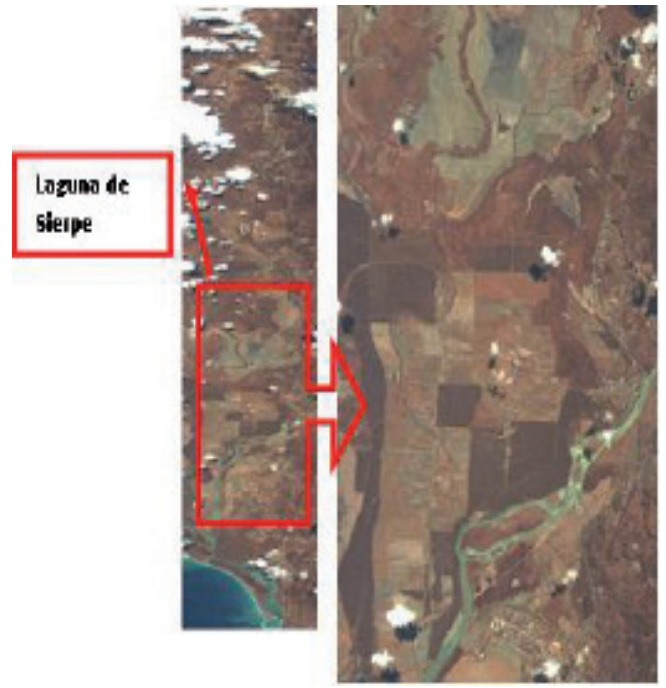

FIGURA 3. Laguna de Sierpe en HYMAP (rgb 20,27,35).

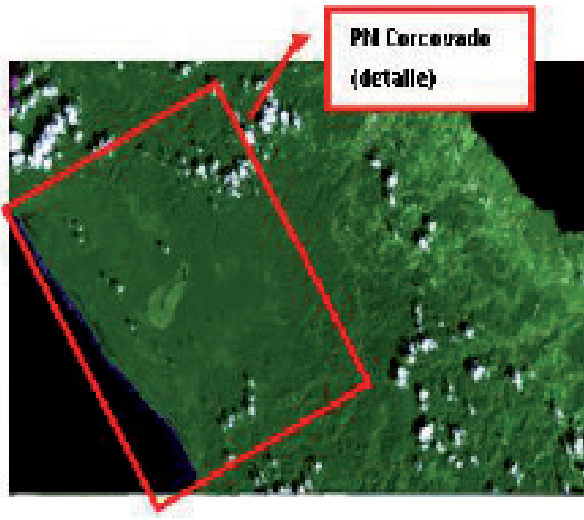

FIGURA 4. Detalle del Parque Corcovado en ETM+ (rgb 7,5,3). 
En agosto de 2010 y febrero de 2012 se ha llevado a cabo un reconocimiento sobre el terreno, que ha permitido muestrear 29 y 20 puntos respectivamente, medidos en campo y en laboratorio con radiómetros USB400 y ASD FieldSpec. Los espectros se han utilizado para caracterizar los materiales y para comprobar la reflectancia de las imágenes HyMAP y MASTER mediante una regresión empírica lineal.

Se ha contrastado la georreferenciación de las imágenes mediante 25 puntos de chequeo medidos en el terreno con GPS en proyección cartográfica UTM zona 17 y Datum WGS84, obteniendo un error absoluto planimétrico de 3.2 y 1.9 píxeles, respectivamente para las imágenes MASTER y HyMAP.

\section{ANÁLISIS DE COBERTURAS DEL SUELO}

\subsection{Cartografía de la Cobertura del Terreno. Clasificación digital de imagen.}

El objetivo de la clasificación es el reconocimiento de clases o grupos cuyos miembros tengan ciertas características en común. El resultado ideal consiste en obtener clases que sean mutuamente excluyentes y exhaustivas.

Se han aplicado dos tipos principales de clasificación: supervisada, si partimos de un cierto conocimiento sobre la zona a clasificar y a partir del cual obtendremos criterios de clasificación; y no supervisada, si no tenemos ningún conocimiento previo y de lo que se trata es de discriminar píxeles en función de una magnitud cuantitativa de diferenciación entre unos y otros (Mena, J.B. et al 2005). La primera tarea, por lo tanto ha sido definir una leyenda (ver Tabla 3) con las superficies de interés susceptibles de producir una respuesta registrada en el píxeles de $15 \mathrm{~m}$, $20 \mathrm{~m}$ y $30 \mathrm{~m}$ de resolución espacial de la imagen, que abarcara la variabilidad de coberturas y que supusieran a priori un valor añadido a la hora de confeccionar una actualización de la cartografía en un espacio denso y homogéneo como este.

El planteamiento metodológico propuesto está enfocado en la extracción de la información a partir de la propia imagen, minimizando el trabajo de campo y la información procedente de librerías espectrales.

La clasificación digital se ha abordado en dos fases. Primeramente se 
ha aplicado clasificación no supervisada mediante los algoritmos Isodata y el $\mathrm{K}$ Means. A continuación, la clasificación supervisada mediante el método de máxima verosimilitud. Para realizar la supervisión en las áreas de entrenamiento seleccionadas, se ha visitado la zona identificando el tipo de material en las cubiertas de interés.

La clasificación basada en la imagen requiere de un conocimiento previo de las diferentes tipos de superficie presentes, aunque no necesariamente de su firma espectral que se puede extraer de la imagen calibrada. Se han registrado 15 áreas de supervisión y se han realizado medidas de espectros discretos sobre muestras tomadas en varias de las áreas que eran accesibles.

A continuación se muestran los resultados obtenidos tras aplicar ambos métodos de clasificación a las imágenes multiespectrales (Figura 5). Dichas imágenes corresponden a los años 1990 y 2012.
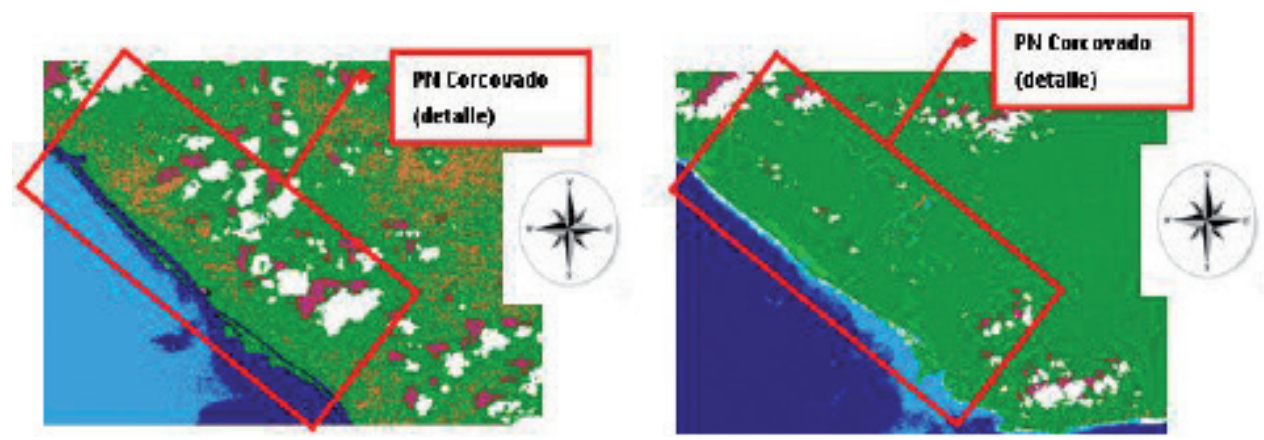

FIGURA 5. Detalle del Parque Corcovado obtenido mediante clasificación supervisada por método de máxima similitud correspondiente a los años 1990 (izqda.) y 2012 (dcha.).

En este caso, la información obtenida de los clusters (clases espectrales) es (Tabla 4): 


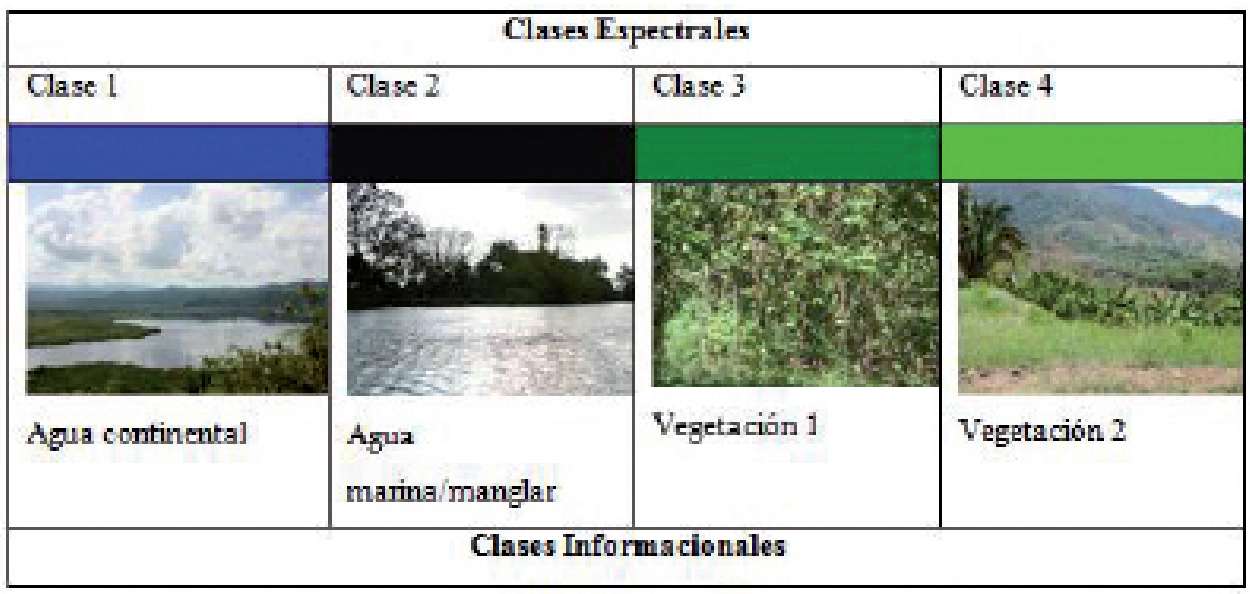

\begin{tabular}{|c|c|c|c|}
\hline \multicolumn{4}{|c|}{ Clases Espectrales } \\
\hline Clase 5 & Clase 6 & Clase ? & Clase $8 /$ Clase 9 \\
\hline & & & Nubes/Sombras \\
\hline Suclo Desmudo & Cultivo 1 & Cultivo & \\
\hline
\end{tabular}

TABLA 4. Clasificación de las clases espectrales de la imagen tras la clasificación supervisada.

(Fuente: Elaboración propia).

Se ha estimado el error y calidad de las clasificaciones digitales obtenidas, calculando la matriz de contingencia y coeficiente Kappa, para lo que se ha considerado como valor real los píxeles semilla supervisados en las campañas de campo de febrero de 2012 (Tabla 5). 


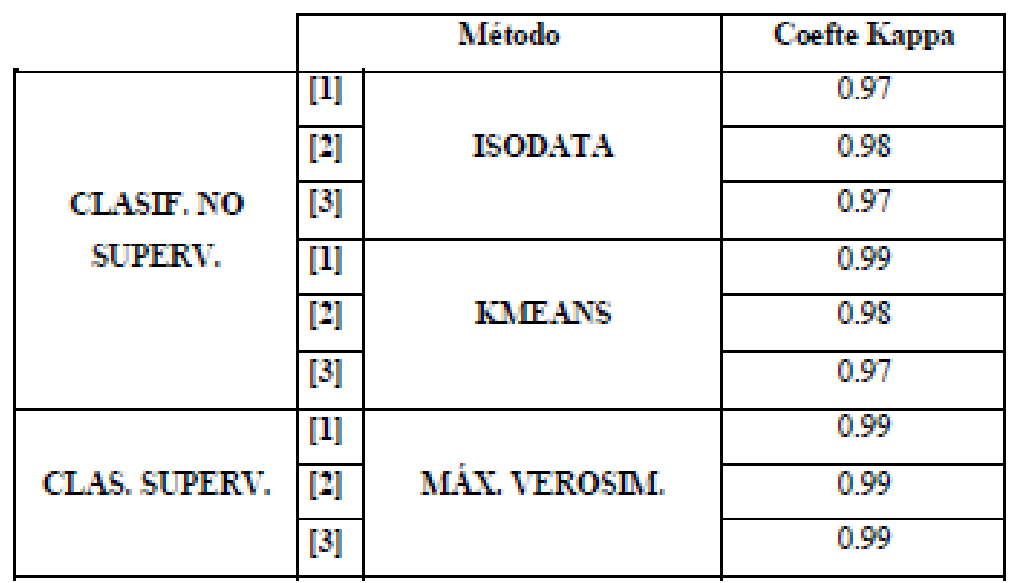

TABLA 5. Tabla resumen con los diferentes coeficientes Kappa obtenidos en las clasificaciones. (Fuente: Elaboración propia).

NOTA: Los números entre corchetes [ ] vienen a referirse a: [1] período 1990-2000,

[2] período 2000-2010 y [3] período 2010-actualidad

Como se puede apreciar, el coeficiente Kappa demuestra que prácticamente existe una buena correlación entre clases y que las designadas para realizar las distintas clasificaciones se asemejan a la realidad. Probablemente el mayor error se haya realizado al clasificar erróneamente y de forma conjunta ciertos elementos de la imagen; por ejemplo, confundir el agua con las sombras, no distinguir los distintos tipos de vegetación.

\subsection{Análisis de cambios de Coberturas del Terreno}

Una amenaza importante en la zona es la deforestación en la reserva forestal Golfo Dulce. Esta reserva forma un corredor que une el Parque Nacional Corcovado con el Parque Nacional Piedras Blancas, asegurando que los animales que necesiten más espacio puedan desplazarse a lo largo del bosque entre ambos parques. 


\subsubsection{Análisis Multitemporal De Cambios}

El análisis multitemporal de la evolución de la cobertura del suelo y las láminas de agua es un tema crítico para entender las condiciones de la misma en el pasado y su potencial futuro en un contexto de cambio climático global. Los sensores HYMAP, MASTER y sobre todo Landsat ETM + proporcionan la capacidad de analizar estas variables a largo plazo, lo que constituye una herramienta esencial para el estudio de la evolución de estos elementos. Esta metodología hace una comparación entre imágenes del mismo lugar pero diferente fecha de toma para poder evaluar el progreso o disminución del cambio, permitiendo un monitoreo de la zona muy útil para medir la deforestación, el volumen de agua, el incremento de zonas agrícolas, etc.

Se han comparado las estadísticas de las clasificaciones en la detección de cambios de coberturas en el período estudiado mediante análisis por pares de fechas, obteniéndose las zonas que han experimentado cambios significativos desde el año 1990 a esta parte (Figura 6).

En el período comprendido entre 1990 y 2000 se ha producido un cambio de un $30 \%$ en la clase "agua" y en torno a un $44 \%$ en la clase "cultivos", ya que zonas en donde había masa forestal se han convertido en zonas agrícolas. Las clases que mayor cambio han experimentado son las "nubes" y "sombras" (en un $20 \%$ aproximadamente), puesto que en el año 1990 había mucha masa nubosa que en el año 2000 se ha visto reducida considerablemente.
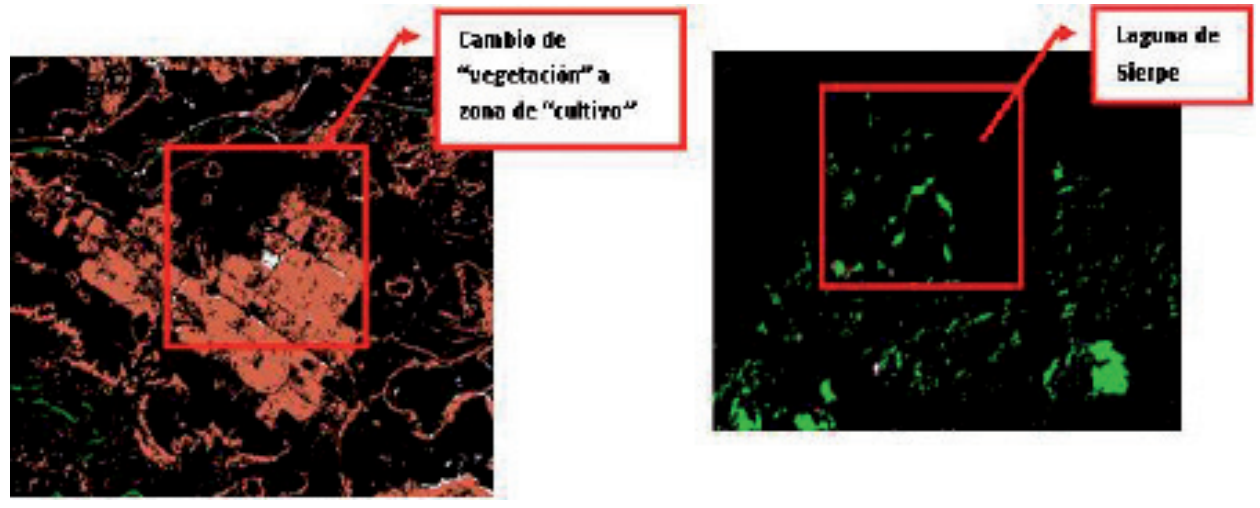

FIGURA 6. Detalle del cambio "vegetación a cultivos" en tono sepia (izqda.) y detalle del cambio de la lámina de agua de la laguna de Sierpe en tono verde (dcha.). 
Estos porcentajes oscilan ligeramente en la siguiente década 2000--2010, ya que la clase "agua" sigue prácticamente presentando la misma variación (29\%), y los cultivos se han visto incrementados en un $10 \%$ aproximadamente. De hecho, las clases que presentan una variación considerable son los "cultivos" y el "agua". En el año 2000, la laguna de Sierpe, por ejemplo, presentaba una capacidad de agua que se ha visto reducida en un $15 \%$ en el 2010 . Y además, algunas zonas de "suelo desnudo" han visto incrementada su área.

Las láminas de agua tanto de la laguna de Sierpe como de los ríos siguen experimentando un ligero cambio desde el 2010 hasta la actualidad. La deposición de sedimentos y la creciente presencia de cultivos en la zona contribuyen notablemente a la afectación y disminución de su caudal.

\subsubsection{Batimetrías por Métodos de Teledetección}

La batimetría permite obtener medidas exactas de profundidad en la zona de estudio, el tipo de fondo y otras propiedades ópticas del agua; sin embargo, este método está limitado por su alto coste operativo y, en ocasiones, su difícil aplicación en aguas poco profundas. La determinación precisa de la profundidad del agua es importante tanto para propósitos de monitoreo submarino como el movimiento de los sedimentos depositados. Una de las aplicaciones dentro de este campo de la teledetección hiperespectral es su empleo en trabajos de batimetría. La mayoría de los estudios de batimetría mediante teledetección hiperespectral (Univ. de Jaén 2012; Degioanni, A. et al. 2002) tienen su fundamento físico en la siguiente función:

\section{Donde:}

$$
L d=L^{*} e^{-g z}+L_{\infty}
$$

Ld: radiancia recibida en el sensor aerotransportado

Ln: término que representa el contraste entre la reflectancia del fondo y reflectancia del agua

en el fondo y la cantidad de agua en la columna.

$L \infty$ : radiancia que recibiría el sensor si el agua fuese ópticamente profunda.

$\mathrm{g}$ : coeficiente de atenuación total difusa

z: profundidad del fondo oceánico

En un primer paso se aplica el Índice de Agua de Diferencia Normalizada (NDWI), que es calculado en base a los niveles digitales de las bandas 2 y 4 de 
Thematic Mapper, es decir, en longitudes de onda entre 520 y 600 nm, y 760 y 900 nm, mediante la aplicación de la ecuación (Castejón López et al., 2010) (2).

$$
\text { (DN2 - DN4) / (DN2 + DN4) }
$$

En este trabajo se ha realizado la batimetría tanto de las zonas costeras como de las láminas de agua continental de la laguna de Sierpe (Figura 7).
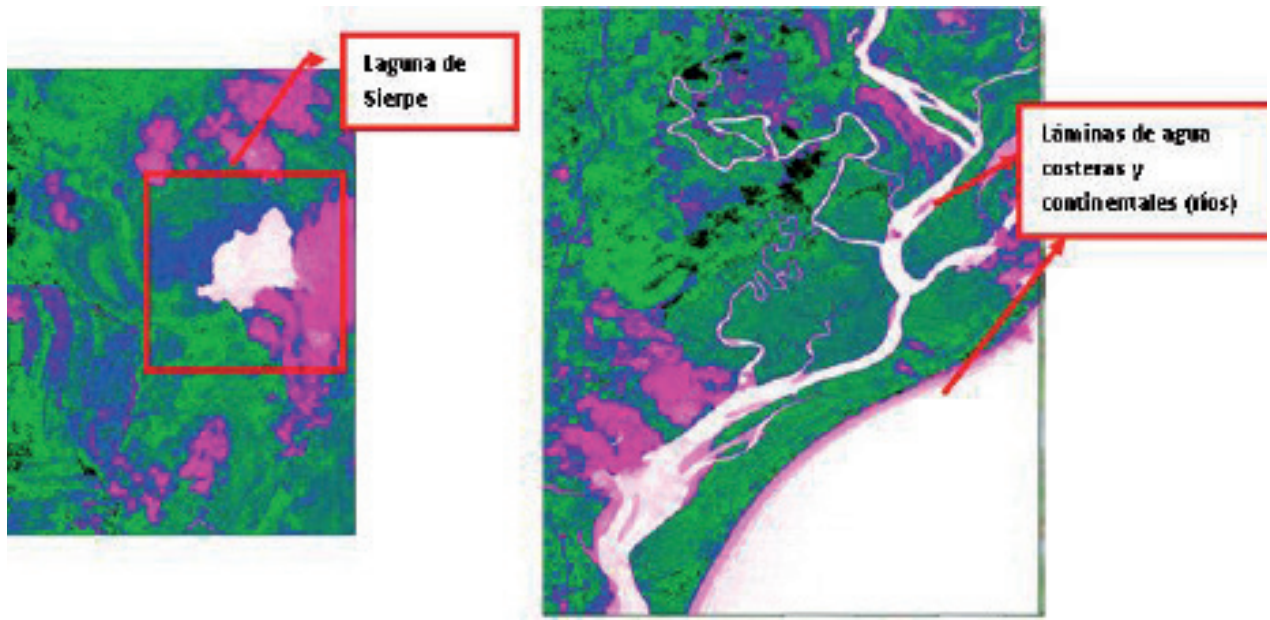

FIGURA 7. Imagen batimétrica de la laguna de Sierpe (decha.) y de zona de ribera y costera (izqda.)

Los valores resultantes de aplicar la ecuación aritmética de la batimetría a cada banda permiten analizar los efectos del sustrato del fondo y de la atenuación por profundidad sobre la radiancia mediante la correlación entre bandas. Así, por ejemplo, se puede apreciar que en las láminas de agua, los tonos rosados más oscuros indican zonas menos profundas, mientras que los más claros, reflejan un mayor nivel de profundidad.

Uno de los casos que más preocupa al Tribunal Ambiental Administrativo (TAA) es la afectación natural de la laguna de Sierpe, ya que está siendo acosada por construcciones en su margen y por cultivos que ya se ubican aproximadamente a un kilómetro del espejo de agua (Figura 8). Según los técnicos del TAA, como consecuencia de las obras en el cauce así como del sedimento proveniente del camino construido, es posible que el flujo del recurso hídrico se haya visto afectado ya que, realizando una comparación de las observaciones en el sitio y los antecedentes 
fotográficos, se ve que ha cambiado significativamente el volumen del flujo de agua entrante a la laguna en la entrada principal de ésta.
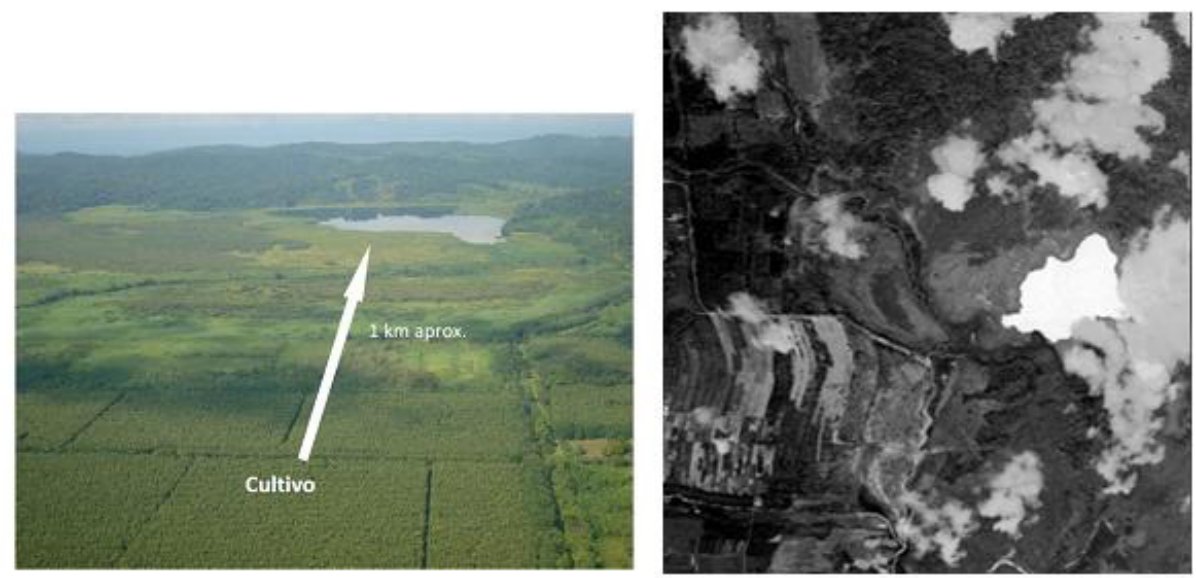

FIGURA 8. Detalle de la separación entre los cultivos (plantación de palma) y la laguna de Sierpe.

(Fuente: Tribunal Ambiental con el apoyo de TNC (The Nature Convervancy) - 2011).

Por ello, el TAA considera necesaria una voz de alerta, a fin de que el MINAET (Ministerio del Ambiente, Energía y Telecomunicaciones), apoyado por el Área de Conservación Osa (ACOSA), investiguen más a fondo la problemática de la laguna Sierpe y realicen un plan de salvamento de este espejo de agua, cada año más reducido.

\section{CONCLUSIONES}

Los resultados confirman la capacidad de los datos hiperespectrales del sensor HyMAP y del sensor MASTER para detectar y cuantificar la distribución efectiva de varios tipos de cubiertas en el área de estudio del sur de Costa Rica. Las imágenes hiperespectrales mejoran la discriminación de estas superficies en procesos estándar de clasificación numérica, si bien se han observado algunos problemas de confusión entre superficies similares que podrían solucionarse introduciendo límites de contorno extraídos de la propia imagen o ampliando el espacio muestral. Así mismo, se ha observado cómo la respuesta de las superficies en el térmico puede ayudar a caracterizar tipos de cubierta.

Se han generado diversos productos cartográficos, de coberturas, de diná- 
mica de cambio y de profundidad, sobre la serie temporal de imágenes. Se aprecia que en las 3 décadas que abarca el estudio, ha ido disminuyendo la capacidad de agua de la laguna.

Finalmente, se concluye que la teledetección es una herramienta útil para analizar cambios en la reflectividad y emisividad de las coberturas del terreno y láminas de agua, permitiendo llevar a cabo un completo análisis medioambiental de los efectos de las perturbaciones en el medio.

\section{AGRADECIMIENTOS}

El presente estudio ha sido parcialmente financiado por el proyecto de investigación: multi-rotores UAV de alteraciones hidrotermales de la Cordillera Volcánica de Costa Rica. AL11-PID-16 (Universidad Politécnica de Madrid y la Universidad de Costa Rica) y MACOSACEN, Manejo Comunitario de suelos y aguas en Centroamérica A2/037794/11 (AECID Agencia Española de Cooperación para el Desarrollo Internacional - Universidad Politécnica de Madrid).

\section{REFERENCIAS BIBLIOGRÁFICAS}

- Bosque Sendra J. y Oñate-Valdivieso F. (2010); "Application of GIS and remote sensing techniques in generation of land use scenarios for hydrological modeling". Journal of Hidrology, Volume 395, 15 December 2010.

- Castejón López, Ma José y González Rojas, Juan Carlos (2010); "Batimetría del Mar Menor (Murcia) elaborada con imágenes Landsat 7".

- Chuvieco E. (2002); “Tecnología Ambiental”. Barcelona, Ariel, 2002.

- Cocks T., Jenssen R., Stewart A., Wilson L., Shields T. (1998); "The HyMap Airborene Hyperspectral Sensor: The System, Calibration and Performance". Proc. of 1st EARSel Workshop on Imaging Spectrometry, Zurich, 37-42.

- Conesa García, Álvarez Rojel y Martínez Guevara, J.B. (eds) (2004); "Medio Ambiente, Recursos y Riesgos Naturales - Análisis mediante Tecnología SIG y Teledetección". Departamento de Geografía de la UNiv. de Murcia, Grupo de Métodos Cuantitativos, SIG y Teledetección de la AGE, Murcia (vol. I y II). 
- Degioanni A., Reynero M.A., Cisneros J. y Cantero A. (2002); "Batimetría de lagunas mediante teledetección: ajustes de un modelo empírico en el sureste de Córdoba, Argentina". Revista de Teledetección.Haberyan K.A., Horn S.P. and Umana V. (2003); "Basic limnology of fifty-one lakes in Costa Rica". Revista de Biología Tropical, 51 (1): 107-122.

- Hartshorn G. \& Poveda L. (1983). "Checklist of trees", p. 158-183. in D. Janzen (ed.). Costa Rican Natural History. University of Chicago, Chicago, Illinois.

- Landgrebe D., 1999. "Information extraction principles and methods for multispectral and hyperspectral image data". Ed. C.H.Chen, World Scientific Publishing Co., Inc., 1060 Main Street, River Edge, NJ 07661, USA 1999.

- Marino C.M., Panigada C. and Buetto L. (2001); "Airborne hyperspectral remote sensing applications in urban areas: asbestos concrete sheeting identification and mapping". IEEE/ISPRS Joint Worshop on Remote Sensing and Data Fusion over Urban Areas, 0-7803-7059-7/01.

- McKeown D.M., Jr., Cochran S.D., Ford S.J., McGlon J.C., Shufelt J.A. and Yochum D.A. (1999); "Fusion of HYDICE Hyperspectral data with panchromatic imagery for cartographic feature extraction". IEEE Trans. on Geoscience and Remote Sensing.

- Mena J.B. and Malpica J.A., 2005. "Color image segmentation based on three levels of textura statistical evaluation". Applied Mathematics and Computation, 161 (2005) 1-17.

- Rejas J.G., Malpica J. A. y Martínez R., 2007. "Aplicación de teledetección hiperespectral en la identificación de cubiertas en áreas semi-urbanas". Congreso internacional, $7^{\text {a }}$ Semana de Geomática, Barcelona (España) 20-23 febrero 2007.

- Umaña V., Haberyan G.K. \& Horn S. (1999); "Limnology in Costa Rica", p. 3362. In R.G. Wetzel \& B. Gopal (eds.). Limnology in developing countries. International Scientific Publications, Nueva Delhi, India. 
- Univ. de Jaén. (2012) “Teledetección aplicada”. Ingeniería Cartográfica, Geodésica y Fotogrametría. - http://www.ujaen.es/huesped/pidoceps/telap/lnves_tel/ terrestre.htm. 